\title{
Value-Based Financially Sustainable Behavioral Health Components in Patient-Centered Medical Homes
}

\author{
Roger G. Kathol, $M D^{1,2}$ \\ Frank deGruy, $M D^{3}$ \\ Bruce L. Rollman, MD, MPH
}

${ }^{1}$ Adjunct Professor of Internal Medicine and Psychiatry, University of Minnesota, Minneapolis, Minnesota

${ }^{2}$ President, Cartesian Solutions, Inc, Burnsville, Minnesota

${ }^{3}$ Woodward-Chisholm Chair and Professor of Family Medicine, University of Colorado School of Medicine, Denver, Colorado

${ }^{4}$ Professor of Medicine, Psychiatry, and Clinical and Translational Sciences, University of Pittsburgh, Pittsburgh, Pennsylvania

Conflicts of interest: Dr Katbol is owner and president of Cartesian Solutions, Inc, a medical management consulting company specializing in bealth complexity and integrated service delivery. Drs deGruy and Rollman do not bave conflicts of interest.

\section{CORRESPONDING AUTHOR}

Roger G. Kathol, MD

3004 Foxpoint Road

Burnsville, MN 55337

katho001@umn.edu

\begin{abstract}
Because a high percentage of primary care patients have behavioral problems, patient-centered medical homes ( $\mathrm{PCMHs}$ ) that wish to attain true comprehensive whole-person care will find ways to integrate behavioral health services into their structure. Yet in today's health care environment, the incorporation of behavioral services into primary care is exceptional rather than usual practice. In this article, we discuss the components considered necessary to provide sustainable, valueadded integrated behavioral health care in the PCMH. These components are to: (1) combine medical and behavioral benefits into one payment pool; (2) target complex patients for priority behavioral health care; (3) use proactive onsite behavioral "teams;" (4) match behavioral professional expertise to the need for treatment escalation inherent in stepped care; (5) define, measure, and systematically pursue desired outcomes; (6) apply evidence-based behavioral treatments; and (7) use cross-disciplinary care managers in assisting the most complicated and vulnerable. By adopting these 7 components, PCHMs will augment their ability to achieve improved health in their patients at lower cost in a setting that enhances ease of access to commonly needed services.
\end{abstract}

Ann Fam Med 2014;172-175. doi: 10.1370/afm.1619.

\section{INTRODUCTION}

$\mathrm{T}$ he Affordable Care Act is centered on making health care less expensive and more effective. A cornerstone of this effort is an overhaul of primary care. ${ }^{1}$ Since over $40 \%$ of patients seen in primary care settings have behavioral health conditions, which include mental health and substance use disorders, disabling psychological symptoms and psychosocial stress, and unhealthy behaviors, ${ }^{2}$ comprehensive primary care must necessarily address behavioral health issues.

As the redesign of primary care takes place, insufficient attention to the critical behavioral elements of comprehensiveness will compromise the gains that are otherwise possible. And gains are possible: behavioral comorbidity, especially in patients with chronic and complex medical conditions, is associated with an estimated $\$ 350$ billion per year spent on unnecessary medical and surgical services when behavioral conditions remain ineffectively treated. ${ }^{3}$ Unfortunately, two-thirds of patients with significant behavioral conditions receive no treatment at all, ${ }_{1}^{4}$ and most of those who do, receive their care in the medical and not the behavioral care sector. ${ }^{5,6}$ Moreover, this percentage does not change even for patients with severe mental disorders.

While financial support for services delivered to patients seen in behavioral health settings remains important, this paper is focused on improving behavioral health care in the primary care setting, where the majority of patients with such problems are encountered. Today, hospitals, clinic systems, groups of primary care physicians, payors, and other stakeholders are seeking economically feasible ways to include behavioral health services that will add value, ie, improve health at equivalent or reduced cost, for patients seen in patient-centered medical homes (PCMHs). This paper describes 7 programmatic components of compre- 
hensive primary care that add value and sustainability of behavioral health care in the PCMH that should be considered as primary care practitioners attempt to improve the health outcomes for patients in their clinical settings by initiating integrated behavioral health services.

\section{THE PROBLEM}

Mild behavioral symptoms might spontaneously resolve or can be addressed during typical doctorpatient interactions, but nearly $70 \%$ of the more serious behavioral conditions in primary care are neither assessed nor treated. ${ }^{4}$ This is due to several factors, including primary care clinician time constraints, limited behavioral health expertise, and interest in medical rather than behavioral conditions. Moreover, among the one-third who receive treatment, less than $20 \%$ of the behavioral health care is evidence-based, ${ }^{5,6}$ even though insufficient treatment is associated with persistent poor health, medical illness treatment resistance, increased physical illness complication rates, impaired function, high direct and indirect total health-related costs, worse health-related quality of life, and premature death. ${ }^{7-9}$ Yet, the addition of integrated behavioral health care, when evidence-based and appropriately configured, can improve health and decrease the total cost of care, ie, can reverse these negative outcomes. ${ }^{10}$

Presently, most primary care clinics include neither systematic approaches nor specialty personnel to address the behavioral health care needs of their patients. Clinics cannot afford onsite mental health professionals, yet are overwhelmed with just meeting patients' medical needs. ${ }^{11}$ Indeed, most savings derived from providing integrated care are likely to accrue to the payer, not the clinic, thus making investment in behavioral services by clinics impractical. To complicate matters, when the limits of primary care physicans' time and expertise are exceeded by patients with behavioral health care needs, physicians tend to refer patients to the mental health sector, where one-half of referred patients never complete the referral ${ }^{12}$ and the other half usually experience protracted delays for appointments with overbooked behavioral clinicians..$^{13}$

A growing number of primary care clinics are recognizing the importance of addressing behavioral issues in an integrated fashion as they transition to PCMHs. The most economically feasible way for primary care clinics to incorporate behavioral expertise into their practices is to hire counselors, social workers, or staff with equivalent training to assist with screening and treatment of common behavioral conditions. While the counseling sessions offered by these clinicians may bring higher patient satisfaction, evidence indicates that counseling short of evidence-based psychotherapy is not associated with long-term health outcomes or with lower total health care expenditures. ${ }^{14,15}$ Let us repeat that: counseling is not the application of evidence-based psychotherapy and is not effective at improving longterm health and cost outcomes.

\section{RECOMMENDATIONS}

It is time for PCMHs to reconsider which behavioral services are most effective for which of their patients, and how they should be deployed. We, therefore, recommend the following:

First, PCMHs with onsite behavioral services should focus most of their case-finding efforts and treatment resources on patients with chronic medical conditions, eg, diabetes mellitus, asthma, coronary artery disease, and those patients with high health care costs, rather than conduct universal screening of all patients for behavioral problems to identify patients for treatment.

Second, treatment resources should be deployed in a fully integrated fashion, according to the criteria outlined in Table 1.

Third, ensure that behavioral clinicians involved in care and PCMH care support have sufficient training and experience to deliver evidence-based behavioral treatments that have been proven effective at improv-
Table 1. Seven Programmatic Components of Comprehensive Primary Care that Add Value and Sustainability of Behavioral Health Care in the PCMH

1. Make behavioral clinicians part of "medical" clinician networks and pay for behavioral health through general medical/surgical benefits

2. Use consolidated medical and behavioral electronic health records (EHRs), registries, and claims data to proactively identify patients with greater health complexity for targeted assessment and treatment of behavioral health conditions

3. Assign geographic or virtual onsite behavioral "teams" with various levels of expertise, including nurses, social workers, PhD/PsyD psychologists, and psychiatrists as integral members

4. Match the level of behavioral health professional expertise to the clinical needs of the patient and escalate behavioral health treatment intensity when improvement fails to occur

5. Prospectively define desired medical and behavioral health outcomes and evaluate success towards these goals in real time, as treatment is given

6. Apply evidence-based treatment algorithms and protocols as standard behavioral health interventions

7. Use care coordinators trained in cross-disciplinary medical and behavioral support to create an integrated, comprehensive, whole-person personal care plan-to help patients with high health complexity overcome clinical and non-clinical barriers to improvement 
ing long-term health status. Low-cost but undertrained clinicians are a poor investment unless linked to ways in which they can support application of evidencebased approaches to treatment in those with behavioral health conditions.

Fourth, programs that target more medically complicated patients, such as the TEAMcare intervention for depressed diabetic and cardiac patients, ${ }_{1}^{16}$ have demonstrated that long-term clinical, functional, and cost improvement occurs when medically complex or high utilizing patients are targeted for a stepped approach to care. ${ }^{16-18}$ Further, care efficiency using newer evidence-based approaches should also be used, such as care coordinator-supported telephonic and non-telephonic behavioral health interventions ${ }^{19,20}$

\section{IMPLICATIONS}

The strategy we advocate would change the approach to behavioral health care in PCMHs in several fundamental ways to achieve the triple aim of an improved patient experience, population health, and lower per capita cost. ${ }^{21}$

First, payment for behavioral health specialists would be a part of the PCMH total health budget. All clinicians involved in patients' care, whether medical or behavioral, would be accountable for overall health outcomes within a single and coordinated budget.

Second, targeted screening using electronic health records to identify comorbid high-need, high-cost, and poorly medically controlled "complex" patients would replace universal behavioral screening.

Third, all PCMH team members would work together toward a goal of concurrent medical and behavioral symptom reversal which, in turn, is associated with lower unnecessary emergency room use, hospitalizations, testing, and procedures. ${ }^{17}$

Fourth, this strategy recognizes the necessity to deploy behavioral clinicians with the expertise to provide evidence-based treatments that are effective at improving outcomes. Patients with more serious clinical and cost consequences from their behavioral comorbidity often require second- or third-step treatments, which require the competence of highly trained behavioral professionals, such as experienced psychiatrists and psychologists, who can help manage firstand second-line treatment failures.

Fifth, it is a more efficient use of limited resources to focus on patients with expensive, potentially reversible conditions, which should produce marked and persistent cost savings as long as "treat-to-target" approaches are used. ${ }^{22}$

Sixth, it would adopt measurement-based outcomes, which require the routine assessment of and progress toward achieving targeted clinical, functional, quality of life, and satisfaction goals. This makes it more likely that the therapeutic focus will remain on returning patients to health while reducing impairment and suffering, and more likely that such therapeutic efforts will succeed. ${ }^{23}$

Seventh, it would utilize trained cross-disciplinary care managers to coordinate care across the inpatient to outpatient to community medical-behavioral continuum $_{i}$ this increases the likelihood that those most in need will, in fact, improve. ${ }^{24}$

Using these strategies, overall health improvement, less expensive care, and improved function in many chronically ill patients can be expected.

Table 1 summarizes programmatic steps that can improve long-term health and reduce cost compared with today's emerging national norm for integrated care. Today we have begun to use meager PCMH budgets to hire low-cost (and insufficiently trained) behavioral clinicians, who are then given responsibility for detecting and managing large populations of general practice patients. This model of integrated care will not lead to desired health and cost outcomes. ${ }^{14}$

We recognize that hardly any programs in the existing payment environment have incorporated our 7 core components. Moreover, few behavioral specialists with the requisite expertise are willing to practice in primary care settings in which inadequate payment is the norm, where PCMHs cannot afford to support them. ${ }^{25}$

Finally, the success of integrated, whole-person care will depend on a new kind of contract with health plans (or employers, or directly with patients) for services-one that includes behavioral services by behavioral professionals as part of expected and paid medical benefits. Segregated behavioral payments, distributed by managed behavioral health insurers, whether independently owned and operated (carved-out) or part of a medical health plan (carved-in), prevent integration of medical and behavioral services. ${ }^{26}$ Thus, PCMHs wishing to contribute to the triple aim through delivery of cost effective behavioral services and also wishing to meet the credentialing requirements for clinically integrated networks and accountable care organizations must alter their provider contracts. Updated medical health plan contracts would include the same direct payment for behavioral professionals' services as to all other medical providers, thus allowing full network participation and fair reimbursement for behavioral clinicians in the PCMH setting. During this transition, care should be given to maintaining financial support from the consolidated budget for behavioral services required for seriously mentally ill patients continuing to receive treatment in a smaller but necessary specialty behavioral health sector. ${ }^{27}$ 
Value-added and sustainable approaches to the delivery of behavioral health care in the PCMH have been given limited attention. This article recommends that 7 core components should be consistently included in the development of PCMHs as care delivery reform progresses. Unaddressed or ineffectively addressed behavioral health conditions in the PCMH predict poor medical and behavioral health outcomes and continued high cost of care. It cannot be overlooked any longer.

To read or post commentaries in response to this article, see it online at http://www.annfammed.org/content/12/2/172.

Key words: integrated care; patient-centered medical home; health reform; primary care; behavioral health; financially sustainable

Submitted June 8, 2013; submitted, revised, November 13, 2013; accepted December 10, 2013.

\section{References}

1. Starfield B, Shi L, Macinko J. Contribution of primary care to health systems and health. Milbank Q. 2005;83(3):457-502.

2. Ansseau M, Dierick M, Buntinkx F, et al. High prevalence of mental disorders in primary care. J Affect Disord. 2004;78(1):49-55.

3. Melek S, Norris D. Chronic Conditions and Comorbid Psychological Disorders. Seattle, WA: Milliman; 2008.

4. Kessler RC, Demler O, Frank RG, et al. Prevalence and treatment of mental disorders, 1990 to 2003. N Engl J Med. 2005;352(24): 2515-2523.

5. Wang PS, Aguilar-Gaxiola S, Alonso J, et al. Use of mental health services for anxiety, mood, and substance disorders in 17 countries in the WHO world mental health surveys. Lancet. 2007;370(9590): 841-850.

6. Wang PS, Berglund P, Olfson M, Pincus HA, Wells KB, Kessler RC. Failure and delay in initial treatment contact after first onset of mental disorders in the National Comorbidity Survey Replication. Arch Gen Psychiatry. 2005;62(6):603-613.

7. Katon WJ, Seelig M. Population-based care of depression: team care approaches to improving outcomes. J Occup Environ Med. 2008;50(4):459-467.

8. Seelig MD, Katon W. Gaps in depression care: why primary care physicians should hone their depression screening, diagnosis, and management skills. J Occup Environ Med. 2008;50(4):451-458.

9. Prince M, Patel V, Saxena $S$, et al. No health without mental health. Lancet. 2007;370(9590):859-877.

10. Kathol RG, Kunkel EJ, Weiner JS, et al. Psychiatrists for medically complex patients: bringing value at the physical health and mental health/substance-use disorder interface. Psychosomatics. 2009; 50(2):93-107.
11. Østbye T, Yarnall KS, Krause KM, Pollak KI, Gradison M, Michener $\mathrm{JL}$. Is there time for management of patients with chronic diseases in primary care? Ann Fam Med. 2005;3(3):209-214.

12. Grembowski DE, Martin D, Patrick DL, et al. Managed care, access to mental health specialists, and outcomes among primary care patients with depressive symptoms. J Gen Intern Med. 2002;17(4): 258-269.

13. Cunningham PJ. Beyond parity: primary care physicians' perspectives on access to mental health care. Health Aff (Millwood). 2009; 28(3):w490-w501.

14. Bower P, Knowles S, Coventry PA, Rowland N. Counselling for mental health and psychosocial problems in primary care. Cochrane Database Syst Rev. 2011;(9):CD001025.

15. Bower P, Rowland N, Hardy R. The clinical effectiveness of counselling in primary care: a systematic review and meta-analysis. Psychol Med. 2003;33(2):203-215.

16. Katon WJ, Lin EH, Von Korff $M$, et al. Collaborative care for patients with depression and chronic illnesses. $N$ Engl J Med. 2010;363(27):2611-2620.

17. Unutzer J, Katon WJ, Fan MY, et al. Long-term cost effects of collaborative care for late-life depression. Am J Manag Care. 2008;14 (2):95-100.

18. Rollman BL, Belnap BH, LeMenager MS, et al. Telephone-delivered collaborative care for treating post-CABG depression: a randomized controlled trial. JAMA. 2009;302(19):2095-2103.

19. Archer J, Bower P, Gilbody S, et al. Collaborative care for depression and anxiety problems. Cochrane Database Syst Rev. 2012;10:CD006525.

20. Richards D, Richardson T. Computer-based psychological treatments for depression: a systematic review and meta-analysis. Clin Psychol Rev. 2012;32(4):329-342.

21. Berwick DM, Nolan TW, Whittington J. The triple aim: care, health, and cost. Health Aff (Millwood). 2008;27(3):759-769.

22. Katon W, Russo J, Lin EH, et al. Cost-effectiveness of a multicondition collaborative care intervention: a randomized controlled trial. Arch Gen Psychiatry. 2012;69(5):506-514.

23. Unützer J, Chan YF, Hafer E, et al. Quality improvement with payfor-performance incentives in integrated behavioral health care. Am J Public Health. 2012;102(6):e41-e45.

24. Kathol R, Perez R, Cohen J. The Integrated Case Management Manual: Assisting Complex Patients Regain Physical and Mental Health. 1st ed. New York, NY: Springer Publishing; 2010.

25. Kathol RG, Butler M, McAlpine DD, Kane RL. Barriers to physical and mental condition integrated service delivery. Psychosom Med. 2010;72(6):511-518.

26. Kathol RG, Melek S, Bair B, Sargent S. Financing mental health and substance use disorder care within physical health: a look to the future. Psychiatr Clin North Am. 2008;31(1):11-25.

27. Manderscheid R, Kathol RG. Fostering sustainable, integrated medical and behavioral health services in medical settings. AIM. 2014:160(1):61-65. 